\title{
Correlation between butyrylcholinesterase variants and sensitivity to soman toxicity
}

\author{
Dimo Dimov'; Kamen Kanev and Ivanka Dimova² \\ 'Disaster Medicine and Toxicology Deparment, Military Medical Academy, Sofia, Bulgaria; 2Department of Medical Genetics, Medical University \\ Sofia, Bulgaria
}

Butyrylcholinesterase ( $\mathrm{BChE}$ ) is synthesized in the liver and found in high concentrations in blood plasma, liver, heart, pancreas, vascular endothelium, skin, brain white matter, smooth muscle cells and adipocytes. BChE is a non specific enzyme that hydrolyzes different choline esters (succinylcholine, mivacurium) and many other drugs such as aspirin, cocaine and procaine. The enzyme is also considered as a bioscavenger due to its ability to neutralize the toxic effects of organophosphorus compounds (nervous system fs agents) such as soman. BChE displays several polymorphisms that influence its serum activity; therefore they could determine the individual sensitivity to chemical nerve agents. In this study, we investigated the correlation between $\mathrm{BChE}$ variants and the degree of enzyme inhibition and reactivation after soman application on blood samples of 726 individuals. The blood samples of individuals expressing abnormal variants, were more sensitive to soman compared to variants of homozygotes and heterozygotes for U-allele. We found significant differences in the degree of enzyme reactivation between different variants (with and without U-presence).

Key words: Butyrylcholinesterase variants, soman toxicity, enzyme inhibition/reactivation

Received: 12 February, 2012; revised: 04 April, 2012; accepted: 18 May, 2012; available on-line: 13 June, 2012

\section{INTRODUCTION}

Cholinesterases are enzymes involved in the metabolism of acetylcholine, anaesthetic drugs (including succinylcholine, mivacurium), cocaine and organophosphates (OP). There are two types of cholinesterases in the human body: acetylcholinesterase and butyrylcholinesterase. Butyrylcholinesterase (BChE) is synthesized in the liver and found in high concentrations in blood plasma, liver, heart, pancreas, vascular endothelium, skin, brain white matter, smooth muscle cells and adipocytes (Kutty, 1980; Chatonnet \& Lockridge, 1989; Oreskovic \& KunecVajic, 1992). For a long time the physiological function of $\mathrm{BuChE}$ was unclear. Nowadays, roles for $\mathrm{BuChE}$ have been suggested in cellular adhesion and neurogenesis (Whyte \& Greenfield, 2003; Paraoanu et al., 2006), myelin maintenance (Neustein et al., 2009), lipoprotein metabolism (Valle et al., 2006), in the processing of the amyloid precursor protein (Rocchi et al., 2003), and as a scavenger of toxic chemicals (Raveh et al., 1997). Organophosphorus compounds (pesticides, nerve agents) are still considered as important chemicals acting on living organisms and some of them widely are used in human practice. Nerve agents (soman, sarin, etc.) are the most lethal chemical warfare agents. They affect the transmission of nerve impulses in the nervous system due to inhibition of acetylcholinesterase. This leads to contraction of muscles, profuse salivation, convulsions, and eventual death by asphyxiation. Butyrylcholinesterase is a naturale countermeasure against organophosphorus agents. It acts as a scavenger in the blood stream before the nerve agent reachs and binds to acetylcholinesterase in the nervous system. However, there are several BChE phenotypes that are genetically determined. People with genetically low BChE activity are considered to be at a higher risk when exposed to organophosphorus compounds (Timothy et al., 2010).

In the context of our study we are interested in phenotypic characteristics such as serum butyrylcholinesterase activity and degree of inhibition by specific inhibitors, which are results of certain genetic polymorphisms.

The genetic polymorphisms of butyrylcholinesterase determine not only the level of serum activity, but also its functional characteristics such as substrate specificity and sensitivity. Different variants show divergent ability to hydrolyze certain chemicals or to be suppressed by certain agents. Studies have shown that the degree of enzyme inhibition by dibucain and sodium fluoride can be used to identify the variants of the enzyme. These facts make it possible to analyze the biochemical properties of different variants of the enzyme, assumed to be associated with a given genotype. Application biochemical criteria for determining the frequency of the most common phenotypes of BChE and thereby inferring its genotypes, respectively, is widely used because of its accessibility and cost-effectiveness.

All these assumptions prompted us to investigate the relation between butyrylcholinesterase variants and sensitivity to soman toxicity.

\section{MATERIAL AND METHODS}

Subjects. The study included 726 individuals -302 females and 425 males, aged $35.3 \pm 9.7$ years. The participants were randomly selected Bulgarian citizens undergoing prophylactic examinations. They provided $10 \mathrm{ml}$ of whole blood. An ethics committee approved the study, and written informed consent was obtained from the patients. The selected individuals were asymptomatic, with serum activity of hepatic enzymes ALT and AST in the reference range. The serum was separated after centrifugation and stored at $-20^{\circ} \mathrm{C}$ before further use.

e-mail: idimova73@yahoo.com

Abbreviations: BChE, butyrylcholinesterase; $\mathrm{DN}$, dibucaine number; DNTB, beta dystrobrevin; FN, fluoride number; OP, organophosphates; UI, units 
BChE activity measurement and determination of $\mathbf{B C h E}$ phenotype. Measurements were performed according to a standard method using propionylthiocholine as substrate. This method was introduced by Dietz and it is based on hydrolysis of thioesters by $\mathrm{BChE}$ derived from human serum (Dietz et al., 1973). The concentration of products of the hydrolysis is directly proportional to the $\mathrm{BChE}$ activity (UI/L at $37^{\circ} \mathrm{C}$ ) and can be detected spectrophotometrically. In the presence of inhibitors dibucaine and sodium fluoride the intensity of produced color is changed and on this way different variants of $\mathrm{BChE}$ can be distinguished. The method is universal and it continues to be used in recent population studies (Cerf et al., 2002; Asad VaisiRaygani et al., 2007).

We used a Screen master spectrophotometer with a flow cuvette. Reagents for determination of $\mathrm{BChE}$ activity were propionylthiocholine, DNTB, buffer (TECO diagnostics). These reagents were diluted with $6 \mathrm{ml}$ distilled water and the final concentration of DNTB and propionylthiocholine were $0.4 \mathrm{mM}$ and $4 \mathrm{mM}$, respectively. To $1 \mathrm{ml}$ of this solution was added $0.01 \mathrm{ml}$ undiluted human serum. The absorbance was measured at $405 \mathrm{~nm}$ for $90 \mathrm{~s}$ and it corresponds to BChE activity exprened in units (UI). For determination of dibucaine number (DN) and fluoride number (FN) we used the same reagents diluted with $0.3 \mathrm{mM}$ dibucaine or $40 \mathrm{mM}$ sodium fluoride, respectively. Then we added $0.01 \mathrm{ml}$ of undiluted serum to $1 \mathrm{ml}$ of working solution and measured the BChE activity. From the degree of inhibition, $\mathrm{DN}$ and $\mathrm{FN}$ were calculated. The $\mathrm{BChE}$ phenotypes were determined following the classification based on Dietz (1973).

Analyzing the biochemical properties of the enzyme we determined different BchE variants corresponding to a given genotype, as follows:

Normal variant UU: dibucaine inhibition $(\mathrm{DN})>75 \%$, fluoride inhibition $(\mathrm{FN})>78 \%$ and enzyme activity $>4000$ $\mathrm{U} / \mathrm{L}$.

Atypical (dibucaine resistant) variant AA: (DN) $<25 \%,(\mathrm{FN})>78 \%$ and enzyme activity $<4000 \mathrm{U} / \mathrm{L}$.

Variant AK: $(\mathrm{DN})$ in range 25\%-75\%, (FN)>78\% and enzyme activity $<4000 \mathrm{U} / \mathrm{L}$.

Variant AS: $(\mathrm{DN})<25 \%,(\mathrm{FN})>78 \%$ and enzyme activity $<2000 \mathrm{U} / \mathrm{L}$

Variant UF: $(\mathrm{DN})>75 \%$, $(\mathrm{FN}) 71-75 \%$ and enzyme activity $>4000 \mathrm{U} / \mathrm{L}$.

Variant US: $(\mathrm{DN})>82 \%,(\mathrm{FN})>75 \%$ and enzyme activity in range 4000-6000 U/L.

Variant UA: (DN) in range 25\%-75\%,(FN)>78\% and enzyme activity $>4000 \mathrm{U} / \mathrm{L}$.

Determination of specific sensitivity of different BChE phenotypic variants to anticholinesterase agents. To determine the sensitivity of the different $\mathrm{BChE}$ variants to anticholinesterase agents we investigated the degree of enzyme inhibition in the presence of soman. Based on published scientific evidence (Maxwell et al., 1987) for soman inhibiting doses, we performed a series of experiments in vitro with pooled human serum. For our subsequent experiments we selected soman concentrations of $10^{-7} \mathrm{M}$ to reach depression of baseline BChE activity about 60-70\%. Measurements were performed according to the method described above. We performed the inhibition/ reactivation experiments using 50 UU samples, all heterozygotes $(\mathrm{N}=39)$ and all detected abnormal homozygotes $(\mathrm{N}=4)$. All measurements were done three times and average values were considered. Sera of different phenotype variants of butyrylcholinesterase were incubated for $20 \mathrm{~min}$ at $25^{\circ} \mathrm{C}$ with $10^{-7} \mathrm{M}$ soman. After estimation of $\mathrm{BChE}$ inhibition the samples were incubated with reactivator HI- 6 in concentration $10^{-3} \mathrm{M}$ at $25^{\circ} \mathrm{C}$ for $20 \mathrm{~min}$. Then the activity of cholinesterase was determined and the degree of enzyme reactivation $(\mathrm{R})$ was calculated according to the following equation:

$\mathrm{R} \%=[1-(E a-E r) /(E a-E i)] \times 100$,

where $\mathrm{Ea}$ is the activity of native enzyme, $\mathrm{Ei}$ is the activity of soman inhibited enzyme and $\mathrm{Er}$ is the activity of inhibited enzyme after incubation with HI-6 reactivator (Karasova et al., 2010).

Statistical method. The relation of enzyme activity with soman inhibition/reactivation was estimated using chi-square test and $P$-value was calculated. $P<0.05$ was considered significant.

\section{RESULTS}

The 726 individuals tested were grouped in seven groups according to their $\mathrm{BChE}$ phenotypic variants, each corresponding to a particular genotype (Table 1 and 2). The majority of studied population (94.1\%) had the normal phenotype corresponding to UU. The percentage of phenotypes corresponding to U-heterozygotes, was $5.38 \%$ of individuals. Only four individuals from the studied group were detected with phenotypes corresponding to abnormal genotypes (AA, AK and AS) $-0.52 \%$.

After application of soman $\left(10^{-7} \mathrm{M}\right)$ to serum samples, the percentage of inhibition of $\mathrm{BChE}$ was determined. Table 3 shows the range of enzyme inhibition (in \%) for the variants corresponding to homozygote UU, heterozygote $\mathrm{U}$ and abnormal homozygotes. We found no differense in $\mathrm{BChE}$ inhibition between the first two groups - 58.8\% and 59.2\%, respectively. The third group had an increased BChE inhibition after soman application by $10 \%$ to $69 \%$, but the difference was not statistically significant.

In subsequent experiment we studied of reactivation of BChE activity by HI-6. The enzyme reactivation by HI-6 was investigated in serum samples with different $\mathrm{BChE}$ variants. The results are shown in Table 4. The average percentage of $\mathrm{BChE}$ reactivation after soman inhibition in blood samples of U-homozygotes was 7.15\%, in U-heterozygotes $-8.6 \%$ and in abnormal homozygotes - $16.8 \%$. There was a statistically significant differences $(P<0.05)$ in the degree of reactivation between the groups.

From the obtained results, it could be assumed that people without normal butyrylcholinesterase allele will be slightly more sensitive to exposure of nerve agents (soman) and will have an altered therapeutic response to the oxime reactivator HI-6.

Table 1. Determination of BChE variants

\begin{tabular}{llll}
\hline Variant & Enzyme activity (U/L) & DN (\%) & FN (\%) \\
\hline UU & $9010 \pm 2041$ & $82 \pm 1.29$ & $79.6 \pm 1.08$ \\
UA & $5810 \pm 885$ & $71.3 \pm 1.58$ & $80.5 \pm 1.47$ \\
UF & $6875 \pm 745$ & $79.2 \pm 1.24$ & $71.8 \pm 1.62$ \\
US & $5042 \pm 436$ & $84.5 \pm 0.85$ & $78.9 \pm 0.98$ \\
AA & 2978 & 19.8 & 82.4 \\
AK & $3300 \pm 387$ & $59.3 \pm 1.95$ & $80 \pm 0.3$ \\
AS & 1594 & 20.7 & 83.1 \\
\hline
\end{tabular}


Table 2. Frequency of BChE variants in Bulgarian population

\begin{tabular}{lll}
\hline BChE variant & N of individuals & Frequency (\%) \\
\hline UU & 683 & 94.1 \\
UA & 26 & 3.58 \\
UF & 8 & 1.10 \\
US & 5 & 0.7 \\
AA & 1 & 0.13 \\
AK & 2 & 0.26 \\
AS & 1 & 0.13 \\
\hline
\end{tabular}

Table 3. Inhibition of different variants of BChE by soman

\begin{tabular}{ll}
\hline BChE phenotype & Enzyme inhibition mean \% $( \pm)$ \\
\hline UU & $58.8(1.9)$ \\
UA & $57.7(0.8)$ \\
UF & $60.9(1.2)$ \\
US & $59.05(1.3)$ \\
Average & $59.2(1.6)$ \\
AA, AK, AS average & $69(2.5)$ \\
\hline
\end{tabular}

Table 4. Reactivation different variants of BChE by HI-6

\begin{tabular}{ll}
\hline BChE phenotypes & Enzyme reactivation mean $\%( \pm)$ \\
\hline UU & $7.15(1.1)$ \\
UA & 10.6 \\
UF & 8.4 \\
US & 6.8 \\
Average & $8.6(0.9)$ \\
AA, AK, AS average & $16.8(0.3)$ \\
\hline
\end{tabular}

\section{DISCUSSION}

BCHE plays an important role in the hydrolysis of many exogenous chemicals containing ester bonds: myorelaxants (succinylcholine), local anaesthetics (procaine, chloroprocaine and cocaine), heroin and other drugs. It is also suggested to be a biological scavenger against organophosphorus compounds used as pesticides and nerve agents. Nowadays, more than 100 polymorphisms of BChE have been identified (Shields \& Lewis, 2011). Several genetic variants with altered enzyme activity have been reported, such as the Atypical gene, Fluorideresistant gene, Silent gene, $\mathrm{K}$ variant, J variant and $\mathrm{H}$ variant (Masato et al., 1997).

Individuals carrying abnormal inactivating alleles have been shown to have a lower capacity to interact with and detoxify drugs. Many surveys indicate an individual's genotype carring some of these variants may result in higher sensitivity to organophosphorus compounds (Loewenstein-Lichtenstein et al., 1995; Dunn et al., 1997; Howard et al., 2010). According to these data it seems reasonable to investigate potential correlation between $\mathrm{BchE}$ phenotypes and the degree of soman inhibition and following reactivation by HI-6. In our study we chose soman because it is one of the most dangerous cholinesterase inhibitor and the most difficult for treat- ment (Bajgar, 2010). In this light we expected the differences of degree of inhibition between different BChE variants to be more remarkable. The mechanism of action of HI-6 as a reactivator is clear. HI-6 is considered to be highly effective in restoring cholinesterase activity in case of soman exposure (Johnson et al., 2000).

In this study we established that abnormal variants of BChE lead to only slight changes of sensitivity to soman. We found that phenotypes corresponding to U-absence showed higher degree of inhibition by soman, not reaching statistical significance. Furthermore, reactivation of variants $\mathrm{AA}, \mathrm{AK}$ and $\mathrm{AS}$ was statistically higher than of the other $\mathrm{BChE}$ variants. These results support the proposal that mutations could affect the conformation and reactivity of the active site of enzyme (Masson et al., 1997). Moreover, based on the present results we can assume that there is a marginal correlation between butyrylcholinesterase variants and sensitivity to soman toxicity, but a significant correlation with the enzyme reactivation.

\section{CONCLUSION}

Polymorphisms in the $\mathrm{BChE}$ gene influence marginally individual sensitivity to soman and significantly ability for enzyme reactivation. Our findings indicate that people carrying abnormal $\mathrm{BChE}$ variants could be more sensitive to the toxic effects of organophosphates. Also, the results allow us to suggest that abnormal BChE variants could explain unexpected effects during therapy with oxime reactivator. This is a preliminary study, which should be extended to a larger population and complemented by DNA analysis of BChE variants.

\section{Acknowledgment}

The publication of the manuscript was supported by project BG051PO001/3.3-05-00 "Science and Business", Operative program "Development of Human resources", European Social Found.

\section{REFERENCES}

Asad Vaisi-Raygani, Zohreh R, Hadi K, Haidar T, Mahdi A, Amir K, Aliakbar Vaisi-Raygani, Tayebeh P (2007) Determination of butyrylcholinesterase (BChE) phenotypes to predict the risk of prolonged apnea in persons receiving succinylcholine in the healthy population of western Iran. Clinical Biochemistry 40: 629-633.

Bajgar J (2010) Optimal choice of acetylcholinesterase reactivators for antidotal treatment of nerve agent intoxication. Acta Medica 53: 207-211.

Cerf C, Mesguish M, Gabriel I, Amselem S, Duvaldestin P (2002) Screening patients with prolonged neuromuscular blockade after succinylcholine and mivacurium. Anesth Anal 94: 461-466.

Chatonnet A, Lockridge O (1989) Comparision of butyrylcho-linesterase and acetylcholinesterase. Biochem J 260: 625-634.

Dietz A, Rubinstein H, Lubrano T (1973) Colorimetric determination of serum cholinesterase and its genetic variants by the propionylthiocholine-dithiobis(nitrobenzoic acid)procedure. Clin Chem 19: 1309-1313.

Dunn M, Hackley B, Sidell F (1997) Pretreatment for nerve agent exposure. In Medical Aspects of Chemical and Biological Warfare. Zajtchuk R, Bellamy R, eds, pp 181-196. Walter Reed Army Medical Center, Washington.

Howard T, Hsu F, Grzywacz J, Chen H, Quandt S, Vallejos Q, Whalley L, Cui W, Padilla S, Arcury T (2010) Evaluation of candidate genes for cholinesterase activity in farmworkers exposed to organophosphorous pesticides-association of SNPs in BCHE. Environ Health Perspect 118: 1395-1399

Johnson M, Jacobsen D, Meredith T, Eyer P, Heath A, Ligtenstein D, Marrs T, Szinicz L, Vale J, Haines J (2000) Evaluation of antidotes for poisoning by organophosphorus pesticides. Emergency Med 12: 22-37

Karasova J, Kassa J, Pohanka M, Musilek K, Kuca K (2010) Potency of HI-6 to reactivate cyclosarin, soman and tabun inhibited ace- 
tylcholinesterase - in vivo study. Letters Drug Design \& Discovery 7: 516-520.

Kutty K (1980) Biological function of cholinesterase. Clin Biochem 13: 239-243.

Loewenstein-Lichtenstein Y, Schwarz M, Glick D, Norgaard-Pedersen B, Zakut H, Soreq H (1995) Genetic predisposition to adverse consequences of anti-cholinesterases in 'atypical' BCHE carriers. Nat Med 1: 1082-1085.

Masato M, Kayoko S, Dilip C, Jinko I, Masakazu I, Kazuo K, Takashi K (1997) Genetic mutations of butyrylcholine esterase identified from phenotypic abnormalities in Japan. Clin Chem 43: 924-929.

Masson P, Froment M, Bartels C, Lockridge O (1997) Importance of aspartate-70 in organophosphate inhibition, oxime re-activation and aging of human butyrylcholinesterase. Biochem J 325: 53-61.

Maxwell D, Brecht K, O’Neill B (1987) The effect of carboxylesterase inhibition on interspecies differences in soman toxicity. Toxicology Letters 39: 35-42.

Neustein S, Eisenkraft J, Cohen E (2009) Aneasthesia for thoracic surgery. In Clinical Anesthesia. Barash P, Cullen B, Stoelting R, Cahalan M, eds, pp 1032-1065. Lippincott Williams \& Wilkins, Philadelphia.

Oreskovic K, Kunec-Vajic (1992) Pseudocholinesterase in aloxan-diabetic rats. Res Commun Chem Pathol Pharmacol 78: 117-120.

Paraoanu L, Steinert G, Klaczinski J, Becker-Röck M, Bytyqi A, Layer P (2006) On functions of cholinesterases during embryonic development. J Mol Neurosici 30: 201-204.
Raveh L, Grauver E, Grunwald J, Cohen E, Ashani Y (1997) The stoichiometry of protection against soman and VX toxicity in monkeys pretreated with human butyrylcholinesterase. Toxicol Appl Pharm 145: 43-53.

Rocchi A, Pellegrini S, Siciliano G, Murri L (2003) Causative and susceptibility genes for Alzheimer's disease. Brain Research Bulletin 61: $1-24$.

Shields K, Lewis J (2011) The Identification of Butyrylcholinesterase (BCHE) Polymorphisms in a Small Australian Defence Force Cohort. bttp:// www.dsto.defence.gov.au/corporate/ reports/DSTO-TR-2503.pdf.

Timothy D, Fang-Chi Hsu, Grzywacz J, Chen H, Quandt S (2010) Evaluation of Candidate Genes for Cholinesterase Activity in Farmworkers Exposed to Organophosphorous Pesticides: Association of SNPs in BCHE. Environ Health Perspect 118: 1395-1399

Valle A, O'Connor D, Taylor P, Zhu Gu, Montgomery G, Slagboom P, Martin N, Whitfield J (2006) Butyrylcholinesterase: Association with the Metabolic Syndrome and Identification of 2 Gene Loci Affecting Activity. ClinicalChemistry 52:1014-1020.

Whyte K, Greenfield S (2003) Effects of acetylcholinesterase and butyrylcholinesterase on cell survival, neurite outgrowth, and voltagedependent calcium currents of embryonic ventral mesencephalic neurons. Exp Neurol 184: 496-509. 